\title{
Captivity and habituation to humans raise curiosity in vervet monkeys
}

\author{
Sofia Ingrid Fredrika Forss ${ }^{1,2,3}$ (1) $\cdot$ Alba Motes-Rodrigo ${ }^{1,4} \cdot$ Pooja Dongre $^{1,2} \cdot$ Tecla Mohr $^{1,2} \cdot$ Erica van de Waal $^{1,2}$
}

Received: 30 June 2021 / Revised: 29 September 2021 / Accepted: 27 November 2021 / Published online: 2 December 2021

(c) The Author(s) 2021

\begin{abstract}
The cognitive mechanisms causing intraspecific behavioural differences between wild and captive animals remain poorly understood. Although diminished neophobia, resulting from a safer environment and more "free" time, has been proposed to underlie these differences among settings, less is known about how captivity influences exploration tendency. Here, we refer to the combination of reduced neophobia and increased interest in exploring novelty as "curiosity", which we systematically compared across seven groups of captive and wild vervet monkeys (Chlorocebus pygerythrus) by exposing them to a test battery of eight novel stimuli. In the wild sample, we included both monkeys habituated to human presence and unhabituated individuals filmed using motion-triggered cameras. Results revealed clear differences in number of approaches to novel stimuli among captive, wild-habituated and wild-unhabituated monkeys. As foraging pressure and predation risks are assumed to be equal for all wild monkeys, our results do not support a relationship between curiosity and safety or free time. Instead, we propose "the habituation hypothesis" as an explanation of why well-habituated and captive monkeys both approached and explored novelty more than unhabituated individuals. We conclude that varying levels of human and/or human artefact habituation, rather than the risks present in natural environments, better explain variation in curiosity in our sample of vervet monkeys.
\end{abstract}

Keywords Curiosity $\cdot$ Novelty response $\cdot$ Neophobia $\cdot$ Exploration $\cdot$ Captivity effect $\cdot$ Captivity bias $\cdot$ Human habituation

\section{Introduction}

Due to both feasibility and logistics, most experimental work on animal cognition is performed in captivity. Nevertheless, cognitive experiments are increasingly being carried out with wild populations in ecologically relevant field settings (Morand-Ferron et al. 2011; van de Waal and Bshary 2011; Thornton and Samson 2012; Benson-Amram et al. 2013; Cauchard et al. 2013; Shaw et al. 2015; Rasolofoniaina et al. 2021). Field experiments usually present wild animals with novel problems in the form of puzzle boxes or devices

Sofia Ingrid Fredrika Forss

sofia.forss@ieu.uzh.ch

1 Department of Ecology and Evolution, University of Lausanne, Lausanne, Switzerland

2 Inkawu Vervet Project, Mawana Game Reserve, KwaZulu Natal, Pretoria 3115, South Africa

3 Department of Evolutionary Biology and Environmental Studies, University of Zurich, Zürich, Switzerland

4 Department of Early Prehistory and Quaternary Ecology, Eberhard-Karls-Universität Tübingen, Tübingen, Germany made of anthropogenic materials. Despite habituation to the apparatuses over time, many studies point to individual differences in neophobia and motivation to participate rather than to differences in cognitive capacities between wild and captive individuals (Overington et al. 2011; Benson-Amram and Holekamp 2012; van Horik et al. 2017; Rössler et al. 2020; Martina et al. 2021). These results suggest that, to successfully implement comparisons of further cognitive skills among settings, we need to improve our understanding of how the motivation to interact and explore novelty differs between captive and wild individuals.

In the broadest sense, curiosity is described as "the motivation to seek information about something unfamiliar" (Berlyne 1950; Loewenstein 1994; Byrne 2013; Kidd and Hayden 2015; Gross et al. 2020). This 'novelty-seeking' is notably in the absence of any immediate external reward (Wang and Hayden 2019). In humans, psychologists commonly address curiosity through questionnaires and selfreports (see overview in Gross et al. 2020). In non-human animals, however, identifying curiosity requires measures of more specific behavioural components describing readiness and motivation to gather information about something 
unfamiliar, outside the context of general survival activities (Mettke-Hofmann et al. 2002; Byrne 2013; Hall et al. 2018). Moreover, given the high risks present in most natural environments, many animals have intrinsically strong neophobia, potentially preventing them from engaging in novelty exploration (Barnett 1958; Greenberg 1990a; Mettke-Hofmann et al. 2002). Therefore, it is likely that overcoming neophobia is foundational for when and how wild animals can pursue curiosity driven exploration. Generally, the term neophobia is used to describe "fear" of novelty (Greenberg 1990a, b, 2003; Fox and Millam 2007; Greggor et al. 2016a, b), but since we cannot always infer fearful emotions of animals from novel-object test paradigms, the more commonly used definition is "novelty avoidance" (Misslin and Cigrang 1986; Benson-Amram et al. 2013; Forss et al. 2015; Greggor et al. 2015; Rasolofoniaina et al. 2021). The contrasting response of closely approaching novel stimuli or preferring novelty over familiarity is termed neophilia (Day et al. 2003; Greenberg 2003; Kaulfuß and Mills 2008). Crucially, one needs to keep in mind that being explorative is not the opposite of being neophobic. Instead, explorative behaviours encompass multiple motivational actions relevant to gain information about something unfamiliar (Greenberg 2003; Biondi et al. 2010; Carter et al. 2012; Forss et al. 2017). Therefore, an animal can be both neophobic and simultaneously have a strong exploration tendency (Moretti et al. 2015; Forss et al. 2017). Here, we refer to curiosity as a positive response to novel stimuli expressed through the combination of low neophobia (measured as readiness to approach something new) and subsequent explorative behaviours used by an individual to gather knowledge of new encountered stimuli (measured as exploration events, e.g., handling, sniffing, etc.) (Damerius et al. 2017a).

One extreme case leading to reduced neophobia is the risk-free existence of captive animals (Barnett 1958; Brown et al. 2013). The "captivity effect" or "captivity bias" refers to measurable intra-species cognitive differences between individuals from natural and captive environments (Haslam 2013; Forss et al. 2015; van Schaik et al. 2016; Rössler et al. 2020). Beyond neophobia, a captivity effect has also been described for other behaviours like innovation (BensonAmram et al. 2013; Rössler et al. 2020) and tool use (Kummer and Goodall 1985; Gruber et al. 2010; Shumaker et al. 2011; Haslam 2013). Variation in activity budgets between wild and captive animals (Veasey et al. 1996; Yamanashi and Hayashi 2011) forms the foundation of the argument that the captivity effect results from wild animals being more occupied with foraging and predator vigilance than captive conspecifics (Kummer and Goodall 1985; Brown et al. 2013; Amici et al. 2020). Accordingly, "the free time hypothesis" and "the excess energy hypothesis" propose that captive animals have a surplus of energy and a lower cognitive load allowing for higher levels of exploration and innovativeness than wild conspecifics, who are occupied searching for food, mating partners, or shelter (Kummer and Goodall 1985; Laidre 2008a; McCune et al. 2019; Amici et al. 2020). For example, captive hyenas (Crocuta crocuta) are less neophobic and more explorative than wild conspecifics, thereby outperforming them in certain problem-solving tasks (Benson-Amram et al. 2013). On the other hand, wild Mexican jays (Aphelocoma wollweberi) were faster problem-solvers than captive conspecifics (McCune et al. 2019) and wildcaught and laboratory raised Goffins cockatoos (Cacatua goffiniana) differed mainly in their motivation to participate in an experimental task, but not in their innovation rates (Rössler et al. 2020). Yet, if and what elements of captive life increase exploration tendencies is less clear. Findings from both primates and birds suggest that frequent exposure to human-made artefacts increases task performance as a result of habituation to artificial materials (Gajdon et al. 2004; Laidre 2008b; van de Waal and Bshary 2011; Damerius et al. 2017a, b). In some primate species, like the great apes, neophobia towards novelty is so high that it can be challenging to perform cognitive tasks through presentation of anthropogenic materials in their natural habitats (Forss et al. 2015; Kalan et al. 2019). Despite being exposed to novel objects for multiple months, wild orangutans (Pongo abelii and Pongo pygmaeus) only explored them on the rare occasions when they first observed a familiar human interact with the objects (i.e., human presence induced a curious response) (Forss et al. 2015). In captive orangutans, researchers found that individuals' degree of human orientation was positively correlated with exploration tendency, which in turn enhance their problem-solving skills (Damerius et al. 2017b). Thus, it is likely that, in some species, the captivity effect results from human habituation; captive animals show lower neophobia due to reduced risk perception regarding humans, and they develop stronger interest in novelty following increased experience with anthropogenic artefacts (van de Waal and Bshary 2011; Damerius et al. 2017a, b).

In the present study, we examined the foundations of curiosity by investigating neophobia and exploration tendencies in wild and captive vervet monkeys (Chlorocebus pygerythrus), using both novel-food and novel-object paradigms. Vervet monkeys are a particularly interesting species to address curiosity as they are opportunistic foragers and successfully inhabit anthropogenic environments like agricultural and urban areas, where they frequently exploit human food sources (Wimberger and Downs 2010; Thatcher et al. 2019). As a highly generalist and "nuisance" species, we expect them to show low levels of neophobia and high exploratory tendencies towards novel stimuli (Greenberg 2003; Sol et al. 2011; Tryjanowski et al. 2016; Griffin et al. 2017; Barrett et al 2019; Jarjour et al. 2020). 
Specifically, we aimed to investigate whether curiosity in vervet monkeys is related to habituation to humans or due to low environmental risk and increased free time per se. In the first case, we compared the responses to novel stimuli of captive monkeys to those of wild habituated and wild unhabituated individuals. We predicted that if there existed a captivity effect, wild monkeys (habituated and unhabituated) would show less interest in unfamiliar objects and foods than captive conspecifics. To address the influence of human habituation on curiosity, we performed a separate test to compute the habituation index of each habituated vervet group. We predicted that groups with higher habituation indices would show more curious responses towards the battery of novel stimuli. In addition, for the wild-habituated monkeys, we evaluated whether the habitat structure of the location where the experiments were conducted had any influence on the monkeys' responses. Here, our prediction was that certain habitat structures, like high grass or open savannah, possibly impose higher predation risk and that monkeys would therefore be less motivated to explore in these habitat structures, compared to when the experiments were performed underneath a tree, providing a more protected location. Because sociality is expected to reduce risk perception and the presence of group members has been shown to increase approaches to novel objects in other species (Stöwe et al. 2006; Moretti et al. 2015; Forss et al. 2017), we predicted that in riskier habitat structures, monkeys would approach more in a social context, accompanied by one or more group members. Finally, given that captive and wild monkeys vary in their experiences with human-made artefacts, we used foods and objects of natural and artificial characteristics to evaluate any potential effect of stimuli features.

\section{Methods}

\section{Subjects and study sites}

We collected data on wild vervet monkeys (Chlorocebus pygerythrus) during February and March 2020 at the Inkawu Vervet Project (IVP) field site, located in Mawana game reserve $\left(28^{\circ} 00.327 \mathrm{~S}, 031^{\circ} 12.348 \mathrm{E}\right)$ in KwaZuluNatal, South Africa. The study site is home to multiple wild groups of vervet monkeys, six of which are habituated to humans, regularly observed by researchers, and partake in experimental studies. Our data set comprised four of these groups, three of which are habituated since 2010 (Baie Dankie: $N=57$, Noha: $N=39$, Lemon Tree: $N=24$ ) and the fourth since 2013 (Kubu: $N=19$ ). In addition, the study area sustains at least three unhabituated groups, with many more living throughout the rest of the reserve. To enable data collection on unhabituated monkeys and to record any potential interactions with the novel stimuli, we placed motion-triggered video camera traps below two known sleeping trees of an unhabituated group (Congo: $N=11$ ).

We collected data on the captive population in March 2020 at the Wild Animal Trauma Centre \& Haven (WATCH) vervet sanctuary, in Vryheid, KwaZulu Natal, South Africa. At the time of data collection, the WATCH sanctuary housed three groups of vervet monkeys. For logistical reasons, we only included two groups in our study (Poena: $N=17$ and Boeta: $N=3$ ). Most of the monkeys arrived at the sanctuary and were cared for by humans, since they were a few weeks old, and only a few individuals arrived at a later life stage. At first, infant monkeys arriving at a very young age are housed indoors and bottle nursed by human caretakers. Once they reach 3 months of age, they are slowly integrated into a group of conspecifics of mixed ages. Since the goal is to release these individuals back into their natural habitat (if circumstances allow), caretakers, and occasionally researchers, limit their contact with the monkey groups as much as possible.

\section{Experimental setup}

\section{Habituated groups}

We presented all four habituated groups with eight novel stimuli representing distinct materials, structures, and odours. We categorized four of these items as human-made or processed: boiled pasta (green, red, natural coloured), popcorn, toy mice (with Baldrian herb scent), and plastic toy cars (yellow, blue, green, and red). One item, white seashells, represented a completely natural occurring object. We chose the remaining three items to have "naturalistic features": fish (dead organic material in form of canned sardines), beef meatballs (raw organic material), and rubber butterflies of different colours (man-made material which mimics naturally occurring organisms) [Supplementary information (SI) Fig.S1]. We randomized the order of presentation of the novel stimuli across groups to avoid order effects and presented one type of novel stimulus at a time, on the ground, always with several items of each type to avoid potential monopolization by higher ranking group members. To attract the wild monkeys' attention to the experimental area, prior to the start of the experiment, we placed a handful of familiar food (corn) in the middle of the area where the novel items were spaced out. The habituated monkeys are used to eating corn as this food item has been introduced during both the habituation process as well as during previous experimental studies (van de Waal et al. 2013; van de Waal et al. 2017). Our main goal was to record any potential behavioural reactions towards the novel stimuli after the monkeys had been attracted to the area (within $20 \mathrm{~m}$ ) and thus seen the novel stimuli. We did all experiments 
during the early mornings $1-2 \mathrm{~h}$ after dawn and we presented only one category of novel stimuli per group per day. We video recorded all experiments with Sony handycams HDR-CX200, two mounted on tripods from different angles, and a third that was handheld by an observer zooming in on any observed explorative behaviours. We presented all novel stimuli to the monkeys for $20 \mathrm{~min}$, to allow enough time for lower ranking individuals to also approach in case the most dominant individuals were present at the start of the experiment preventing the lower rankers from approaching. Because the microhabitats vary slightly across groups as well as within each groups' home range, depending on their location on the day of our experiments, we categorized each experimental setup into three distinct habitat structures: open savannah (no canopy protection and no high grass), high grass (high grass but no canopy protection), and below tree (the experimental area was protected by canopy). In the open savannah, vervet monkeys are exposed to aerial predators like eagles and monkeys are observed to restrict their movement in high grass as the study area is home to a high abundance of pythons, capable of capturing vervet monkeys. Consequently, below trees represents the safest habitat structure for the monkeys as the tree canopy serves as protection from aerial predators and these areas do not have high grass.

\section{Unhabituated group}

The unhabituated group would not tolerate any human presence, as individuals from this group run away when human observers approach. They were however already habituated to eat corn when placed out in their habitat. We used an identical set up as with the habituated group, where we placed a small amount of corn in the middle of the area with the novel items. To record data from the unhabituated group, we placed the video camera traps in a way that they captured two different angles of the novel items, which we presented to the monkeys below two of their known sleeping trees. We used all the same novel stimuli as those used for the habituated groups. Because of the uncertainty regarding when the group would pass by the experimental location or when the monkeys would exactly use those sleeping trees, we presented the novel stimuli for 2 days in a row (unless a recording of any approaches by the group took place before the end of 2 consecutive days). Recordings from the camera traps thus allowed us to distinguish whether the group approached the novel stimuli on a single or multiple visits. For comparisons with the other group types, we only used the responses observed during the first visit.

\section{Captive groups}

At the WATCH sanctuary, we placed the novel stimuli in the main enclosure of the monkeys, who we moved into a side enclosure during the preparation of the experiment, and then let back into their normal enclosure. We used the same experimental protocol as for the habituated groups, including categories and numbers of novel stimuli, experimental duration, video camera placements, and recordings. As the captive monkeys were not used to corn, we used a few peanuts instead as the familiar food that would attract their attention to the experimental area.

\section{Video coding and measurements}

We coded all behavioural responses from video recordings. We recorded the number of close proximity approachesthose made to within $1 \mathrm{~m}$ of any of the multiple novel stimuli (food or item) - by any monkey that was present within a $20-\mathrm{m}$ radius of the experimental location. As we defined a close proximity approach as each time a monkey approached within $1 \mathrm{~m}$ the novel stimuli, in any case where a monkey left the experimental area and then approached within $1 \mathrm{~m}$ again, this represented two approaches. For each approach that was made to the experimental area, we also distinguished whether or not the approach was made alone (when no other monkey was present within $1 \mathrm{~m}$ of the novel stimuli) or socially (when there was at least one other monkey present within $1 \mathrm{~m}$ of the novel stimuli). Once a monkey made physical contact with a novel item $(0 \mathrm{~m})$, we coded following exploration events: the number of smelling and tasting events, the number of times a monkey touched the novel item by hand, the number of times when a monkey chewed/ bit the novel stimuli and the number of times a monkey lifted and moved an item. We then summed these behaviours into one exploration score labelled number of exploration events for each group and item. For each novel-food item, we additionally scored whether or not a monkey tasted it, defined as an event where a monkey licked a novel-food item, or every time a monkey put its lips onto a food item without ingesting it. All definitions of the coded behaviours as well as the frequencies of approaches and exploration events per group can be found in the ethogram in Table S1 and Fig. 4S in the Supplementary material.

\section{Habituation test}

To estimate the variation in human habituation among groups, we additionally performed a habituation test with the wild-habituated and captive groups. During this test, we exposed the monkeys to a human male that they had never seen before. The wild-habituated groups are familiar with researchers and project volunteers who attempt to distinguish themselves from other humans such as poachers by always wearing a turquoise blue cap while in the presence of the monkeys. In the habituation test, the man was dressed all in black clothes and wore a black cap. The man walked 
calmly towards the group of the monkeys shaking a Tupperware with corn as this is a familiar signal to the monkeys when they participate in research experiments. In the wild setting the man then placed the closed box with corn at his feet and as a group level habituation index, we measured the proportion of monkeys that approached the man to a distance of $1 \mathrm{~m}$ out of all the monkeys present within $20 \mathrm{~m}$. In the captive setting, the man placed himself right at the enclosure mesh and placed peanuts right at his feet, which were in touchable distance to the monkeys. This test lasted $20 \mathrm{~min}$ in total.

\section{Statistical analyses}

We conducted the statistical analyses in $\mathrm{R}$ (version 3.6.1; R Core Team, 2020) and RStudio (version 1.2.5031; RStudio Team, 2020). We z-transformed covariates (habituation index and group size) to have a mean of zero and standard deviation of one before including them in the models to facilitate the interpretation of the coefficient estimates (Schielzeth 2010).

We first conducted a series of Spearman correlations to investigate whether any of the response measures (number of close proximity approaches, number of exploration events, and number of individuals within each group that tasted the food items) were correlated (Table 2). Since the number of individuals that tasted the different stimuli strongly correlated with the other response measures and this variable contained multiple missing values $(N=24)$, we excluded this variable from further analysis.

To address the study aims, we fitted four different Generalized Linear Mixed Models (glmm) to the data (Table 1). We checked all models (Model 1a,1b, 2, 3) for overdispersion and overall stability (see Supplementary material) and z-transformed continuous variables (Habituation index and group size) before including them as fixed effects (Table 1). We draw inference by comparing the full model with a reduced (null) model lacking the predictors of interest but containing all other model elements (Forstmeier and Schielzeth 2011) using a likelihood ratio test (test "Chisq" in the R function anova, (Dobson 2002). We implemented this approach to avoid "cryptic multiple testing" and to maintain type 1 error rates at the desired nominal level of 0.05 (Forstmeier and Schielzeth 2011). We calculated individual $\mathrm{p}$ values for each predictor using the function drop1 and $\mathrm{R}$ squared using the function r.squaredGLMM.

In the first model (Model 1a), we investigated the effects of group type (three levels: wild habituated, wild unhabituated, and captive) and stimuli type (8 levels, see above) on the number of approaches (response variable, count data) observed in a given group. For Model 1a, which had a Poisson error structure and log-link function, we fitted the

Table 1 Descriptions of the different model structures. Variables preceded by a " $z$ " indicate that this variables were $\mathrm{z}$-transformed before being introduced in the models

\begin{tabular}{|c|c|c|c|c|}
\hline Model & Response variable & Fixed effects & Random effect & Offset \\
\hline $1 \mathrm{a}$ & Number of approaches & $\begin{array}{l}\text { Stimuli type (8 levels); } \\
\text { Group type (3 levels) }\end{array}$ & Group ID (7 levels) & Log group size \\
\hline 1 & Number of approaches & $\begin{array}{l}\text { Stimuli type ( } 8 \text { levels); } \\
\text { Group type }(2 \text { levels })^{\text {a; }} \\
\text { z-Habituation index }\end{array}$ & Group ID (6 levels) & Log group size \\
\hline 2 & Number of exploratory events & $\begin{array}{l}\text { Stimuli type (8 levels); } \\
\text { Group type }(2 \text { levels })^{\text {a }} \\
\text { z-Habituation index }\end{array}$ & Group ID (6 levels) & Log group size \\
\hline 3 & $\begin{array}{l}\text { Two-column matrix including number of social } \\
\text { approaches and number of individual approaches per } \\
\text { trial }\end{array}$ & $\begin{array}{l}\text { Stimuli type (8 levels); } \\
\text { Habitat structure (3 levels); } \\
\text { z-Habituation index; } \\
\text { z-Group size }\end{array}$ & Group ID (4 levels) ${ }^{2}$ & - \\
\hline
\end{tabular}

Group size was log-transformed before being introduced as an offset

${ }^{a}$ Wild habituated groups were excluded from the model as they did not pose a habituation index

${ }^{\mathrm{b}}$ Included as control predictor

Table 2 Coefficients and $\mathrm{p}$ values in parenthesis resulting from the correlation analyses performed among curiosity measures

\begin{tabular}{llll}
\hline & $N$ approaches & $N$ exploratory events & $N$ tasting individuals \\
\hline N approaches & 1 & $0.47(<0.001)$ & $0.45(0.01)$ \\
N exploratory events & - & 1 & $0.61(<0.001)$ \\
N tasting individuals & - & - & 1 \\
\hline
\end{tabular}


function glmer from the package lme4 (Bates et al. 2014). To account for group identity, we included the random intercept of group ID (7 levels, see above) into the model. We also included the logarithm of group size as an offset term to account for the different number of individuals in each of the groups.

To evaluate variation in close proximity approaches in relation to habituation level, we fitted a second model (Model 1b) using the same response variable, random structure, and the same offset as in Model 1a, but we changed the fixed effect structure. In addition to group type (2 levels: wild habituated and captive) and object type, we included the habituation index into Model $1 \mathrm{~b}$. As unhabituated groups did not have a habituation index, we excluded this group from those models where this variable was included (Model $1 \mathrm{~b}$ and Model 2, see below).

In Model 2, we evaluated potential differences in explorative behaviour among the different group types ( 2 levels: wild habituated and captive), habituation level and stimuli type (8 levels). Similar to Models 1a and 1b, in Model 2, we included the random intercept of group ID as well as group size as an offset. To avoid overdispersion problems, we fitted this model using a quasi-Poisson model with a negative binomial distribution and the optimizer "bobyqa".

In Model 3, we evaluated whether the proportion of social approaches varied according to habitat structure, habituation level, and stimuli type. In Model 3, we only included data from wild-habituated groups as these groups were the only ones that had been tested at locations with different habitat structures (below tree: $N=14$, high grass: $N=10$, and open savannah; $N=13$ ). Model 3 was a binomial model with a response variable in the form of a matrix containing two columns corresponding to the number of social approaches and the number of individual approaches per trial (Baayen et al. 2008). Using such response variable, we account for the different number of approaches observed in different trials. Given that binomial models do not allow including offsets, we included group size as a control predictor. As before, we also included the random intercept of group ID was included in the model (although note that in this case group ID only had 4 levels, which is the threshold generally used to substitute a fixed by a random effect, meaning that it could have also been included as a control predictor).

\section{Results}

\section{Relationship between response measurements}

We found that all three response measures were significantly correlated among one another. The strongest correlation was found between the number of individuals tasting the novel stimuli and the number of exploratory events observed in a group. Correlation coefficients and $p$ values of the correlations can be found in Table 2 .

\section{Factors influencing approaches to novel stimuli}

Model 1a was overall significantly different from its corresponding null model (likelihood ratio test: $X^{2}=70.94$, $\mathrm{df}=9, p<0.001 ; R^{2}$ full model $=0.5$; SI: Table $3 \mathrm{~S}$ ). Group type and stimuli type both had significant effects on monkeys' approaches to the novel stimuli (group type: $\mathrm{df}=2$, $p<0.001$; stimuli type: $\mathrm{df}=7, p<0.001$ ). More specifically, we found that the three group types significantly differed among them (Fig. 1), with captive groups presenting the highest average number of close approaches to the novel objects and foods (captive-wild habituated: $p<0.001$, Hedge's $g=0.89$; captive-wild unhabituated: $p<0.001$, Hedge's $g=1.16$; wild habituated-wild unhabituated: $p=0.048$, Hedge's $g=2.23$ ).

The visualization of the effects of stimuli type on the number of approaches by group (SI: Fig. 2S) suggested that the differences among stimuli indicated by the model were driven by the high number of approaches in the largest captive group (Poena). To determine if this was the case, we fitted Model 1a again, but removed the data from the Poena group. In this case, we found that although the fullnull model comparison was significant (likelihood ratio test: $X^{2}=20.92, \mathrm{df}=9, p=0.013 ; R^{2}$ full model $\left.=0.41\right)$ and the significant effect of group type remained $(p=0.002)$, stimuli type did not have a significant effect on the number of approaches $(p=0.34)$.

Model 1b (SI: Table 3S) was overall significant both when the Poena group was included and excluded (with

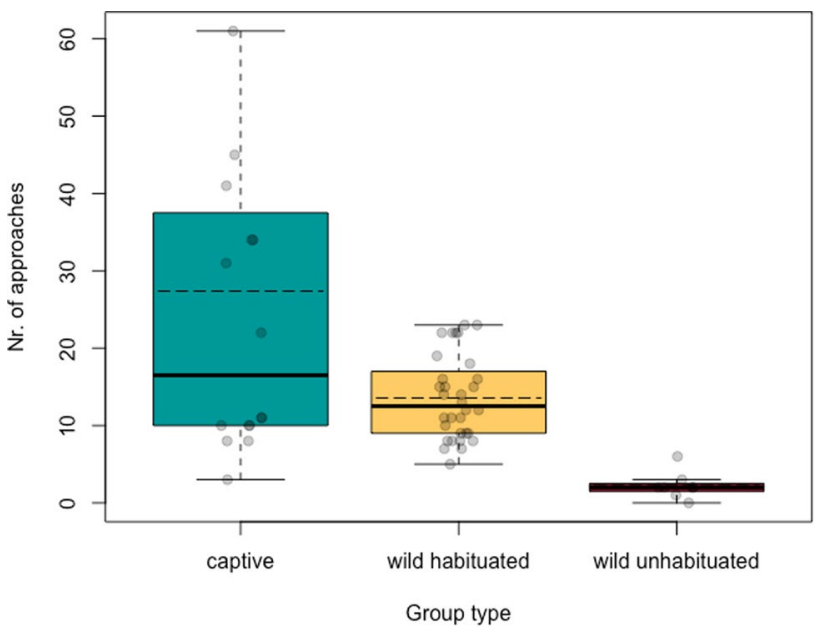

Fig. 1 Boxplots of the number of approaches performed by each group type. Each point corresponds to a trial $\left(N_{\text {captive }}=16\right.$, $N_{\text {wild habituated }}=32, N_{\text {wild unhabituated }}=8$ ). Dashed lines correspond to the group means and solid lines correspond to the group medians 
Poena: likelihood ratio test: $X^{2}=66.83, \mathrm{df}=9, p<0.001$; $R^{2}$ full model $=0.5$; without Poena: likelihood ratio test: $X^{2}=18.18, \mathrm{df}=9, p=0.03 ; R^{2}$ full model $\left.=0.41\right)$. In neither case did the habituation index (with Poena: $p=0.84$, without Poena: $p=0.19$ ) nor the group type (with Poena: $p=0.08$, without Poena: $p=0.09$ ) have significant effects on the number of close approaches observed in the different groups.

\section{Factors influencing exploration tendency}

Model 2 was overall significant according to the full-null model comparison (likelihood ratio test: $X^{2}=67.28, \mathrm{df}=9$,

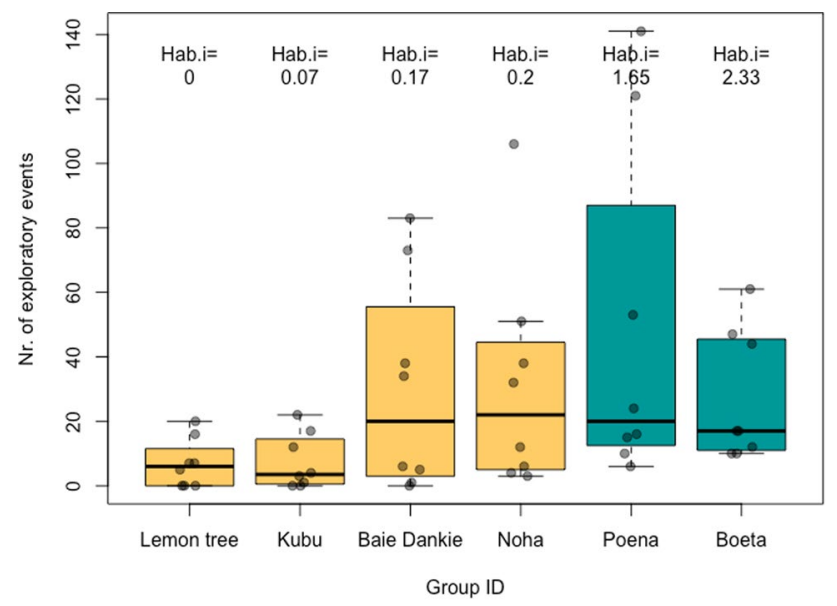

Fig. 2 Boxplots of the number of exploratory events observed in each of the groups. Hab.i represents the habituation index calculated for each group. Green boxes correspond to the captive groups and yellow boxes correspond to wild-habituated groups

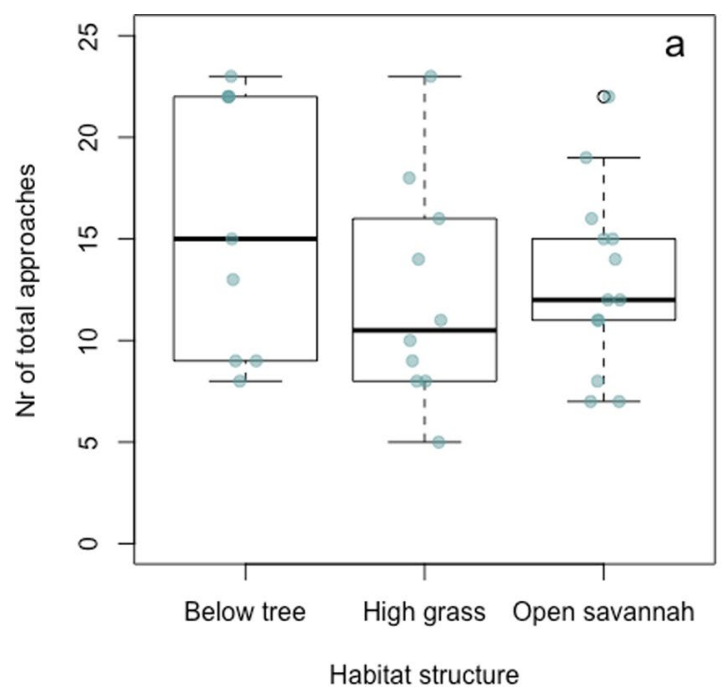

Fig. 3 a Boxplots of the number of total close approaches observed in the different habitat structures and $\mathbf{b}$ the proportion of social approaches out of the total number of approaches (individual and $p<0.001 ; R^{2}$ full model $=0.68$, SI: Table $\left.5 \mathrm{~S}\right)$. All test predictors had a significant effect on the response (habituation index: $p<0.001$, Fig. 2 ; stimuli type: $p=0.001$ ), although the significance of group type (i.e., difference in exploration events between captive and wild-habituated groups) was marginal ( $p=0.047$, Hedge's $g=0.58)$. Visual assessment of the data suggested that the statistical differences in exploration tendency based on stimuli type were not driven by a particular group (SI: Fig. 3S). Differences in exploratory events based on stimuli type were investigated by changing the predictor's reference category (SI: Fig. 3S, Table 6S).

\section{Habitat structure and novelty approaches}

Model 3 was overall significant according to the full-null model comparison (likelihood ratio test: $X^{2}=30.29, \mathrm{df}=10$, $p<0.001 ; R^{2}$ full model $=0.68$, SI: Table $7 \mathrm{~S}$ ). We found that the proportion of social approaches varied significantly across stimuli types $(p<0.001)$. However, the proportion of social approaches did not significantly differ based on habitat structure ( $p=0.47$, Fig. 3 ) or habituation index ( $p=0.99)$.

\section{Discussion}

\section{The effect of human habituation on curiosity}

As opportunistic foragers, we would expect vervet monkeys to show relatively low neophobia to optimize their foraging niche (Greenberg and Mettke-Hofmann 2001; Greenberg 2003; Mettke-Hofmann 2014; Barrett et al. 2019). Our results, however, showed that within this species, neophobia

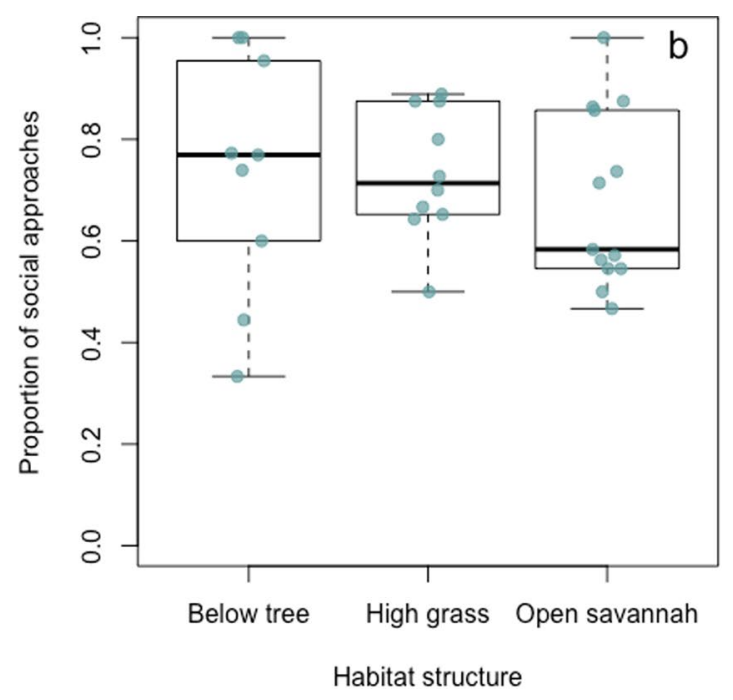

social) observed in each of the experimental locations featuring different habitat structures. Each dot corresponds to a trial 
levels were conditional on environment (captive and wild) and habituation level (Fig. 1). Wild individuals approached novel stimuli significantly less than captive conspecifics and, as predicted, within the wild sample, unhabituated monkeys approached novel items less than habituated individuals (Fig. 1). This contrasts with both the "free time" and "excess energy" hypotheses (Kummer and Goodall 1985; Laland and Reader 1999; Reader and Laland 2001; Amici et al. 2020), which would predict that both types of wild vervet groups (habituated and unhabituated) have similar approach frequencies, since they live in the same environment and therefore experience similar predation pressure, food abundance, and presumably are in need for similar amount of foraging and vigilance activities. Moreover, we exposed the wild unhabituated group to the novel stimuli longer than the habituated monkeys, due to the setup by the video camera traps. Thus, the need for wild individuals to attend to other activities during the experiments cannot account for the observed differences in the number of approaches between these group types. As such, our data do not support the "free time" or "excess energy hypotheses". Rather, we propose the habituation hypothesis as a possible explanation of our findings, and discuss this more below.

Besides differences in the number of close approaches between monkeys from captive and wild habitats, the wild-habituated monkeys made an intermediate number of approaches, in-between their captive and wild unhabituated conspecifics (Fig. 1). The captive monkeys in our sample had never (or only at very early age) experienced any negative reinforcement when approaching anything unfamiliar as they spent all their life within a risk-free, food provisioned habitat and thereby probably have a positive perception of humans. This experience was reflected in the results of the habituation test, as almost all captive monkeys approached the man to the closest possible distance. Of course, we cannot account for the fact that the captive monkeys experienced a barrier between them and the unknown human as he was standing outside the enclosure mesh, however given that the more habituated-wild monkeys also approached to same distance suggest that habituation to humans and/or human artefacts reduces approach neophobia. In contrast to the captive monkeys, the wild monkeys at IVP are exposed to both negative and positive human interactions. Besides researchers (which are distinguished by their blue caps) who sporadically provide food through field experiments, they occasionally encounter poachers, hunters, and people living in villages just outside the reserve fence. Accordingly, the wild-habituated monkeys in our sample have become accustomed to humans and human artefacts but also experience the hazards of natural environments. It is possible that during the experiments, the wild-habituated monkeys perceived researcher presence as a safety indicator, or associated us with occasional feeding opportunities, which possibly raised their motivation to approach the novel stimuli compared to the unhabituated group. Yet, within the sample of habituated-wild monkeys, habituation index did not predict the number of approaches (SI: Table 4S and Fig. 2S), but groups with higher habituation indices had stronger exploration tendencies (Fig. 2). It is also worth emphasising that the majority of the habituated IVP monkeys avoid very close proximity even to familiar humans (Erica van de Waal, personal observation). These findings imply that a significant effect of habituation is the increased motivation to interact and manipulate novel stimuli, rather than just daring to come closer to humans or their artefacts, or expecting to obtain food from them. All together, these findings support our hypothesis that habituation to humans and/or their artefacts facilitates curiosity towards novelty in vervet monkeys.

Going beyond this, within the wild-habituated groups, we found lower explorative tendencies in Lemon Tree and Kubu compared to Baie Dankie and Noha. Indeed, the humanrelated experiences vary between the habituated groups. The home range of Lemon Tree is located furthest away from the IVP station; and in the previous years, both Lemon Tree and Kubu have encountered hunters/villagers more frequently than other groups. During the habituation process of the monkeys at IVP, Lemon Tree showed a delay in their habituation compared to the other habituated groups (Erica van de Waal, personal communication). Thus, it is plausible that the effect of human habituation on novelty responses is relative to the ratio of neutral-positive (researcher) encounters to neutral-negative (non-researchers, poachers, and hunters) encounters experienced by a group. Furthermore, both Lemon Tree and Kubu have participated in fewer field experiments, and thereby experienced less exposure to manufactured materials and food rewards. Moreover, we found that the groups with the higher habituation indices (Poena, Boata, Noha, and Baie Dankie) explored the plastic cars and rubber butterflies more than the two groups with lower habituation index (Kubu, Lemon Tree) (SI: Fig. 3S). Although these groups have more experiences with colourful items and anthropogenic materials, they also explored seashells more than the other groups, an item that was novel but represents a completely natural material (SI: Fig. 3S). These observations suggest that it was not the material per se that captured their interest but rather that habituation brings about a general change in their curiosity towards unfamiliar items, showing strong support for our habituation hypothesis.

\section{Stimuli type and curiosity}

The different stimuli types that we presented to the monkeys did not influence the number of close approaches observed across groups, implying that since all items were new to the monkeys of all groups, each individual needed to approach first to judge whether or not to engage in further exploration. 
The categorization of man-made/processed versus more naturalistic stimuli did not have any general effect on responses (SI: Fig. 3S and Fig. 2S). Instead, the data suggest that items that emit a characteristic odour (fish, meatballs, cat toy mice, and boiled pasta) might be less explored on average than non-smelly items. Furthermore, both captive and wild vervet monkeys seemed reluctant to taste the strong-smelling food items fish and meatballs. Former experiments introducing novel foods have demonstrated that it indeed takes vervet monkeys multiple exposures to novel food before they accept it as a food source (Canteloup et al. 2020, 2021) and sociality plays a role in that monkeys are more likely to eat novel food after first observing a conspecific do so (Pooja et al. in prep). Thus, it is likely that monkeys perceive an unknown smell as repulsive and therefore explored such items less. One could argue that popcorn emits similar levels of odour as boiled pasta, yet popcorn was explored much more by the monkeys, especially by the two groups Baie Dankie and Noha (SI: Fig. 3S). These groups regularly participate in field experiments rewarded with soaked corn, and thus, it is possible that the monkeys of Baie Dankie and Noha associated the smell of popcorn with soaked corn, and thereby had a more positive association with the smell of popcorn compared to the other odours. Future experiments should investigate further the effect that odour cues have on novelty responses and exploration tendencies.

\section{Habitat structure and novelty responses}

Compared to the wild-habituated groups, it is worth noting that the experiments with the unhabituated wild group always took place underneath a familiar, frequently used sleeping tree, where the monkeys are presumably relatively safe from aerial predators, and with no high grass to obscure potentially hidden snakes, yet this did not seem to increase their motivation to approach (Fif.1). Furthermore, even though open savannah exposes vervet monkeys to large birds and areas of tall grass can hide predatory snakes (Seyfarth et al. 1980), habitat structure had no influence on the motivation to approach novelty during our experiments (Fig. 3a). Previous findings suggest that vervet monkeys at IVP vocalize to recruit social partners, especially close to the river (Mercier et al. 2017), proposing that monkeys experience the river bank as a high-risk area. Thus, distance to the river could potentially be a more relevant variable to assess the influence of habitat on novelty responses. In our sample, habitat structure had no effect on whether or not a monkey approached alone or in a social context (Fig. 3b). This finding was somewhat unexpected, given that sociality has been reported to reduce the risk involved in approaching something new (Stöwe et al. 2006; Moretti et al. 2015), and watching a conspecific interact with novelty also increases exploration tendencies (Forss et al. 2017). Of course, social influences may also constrain an animal's motivation to interact with novel stimuli due to monopolization or potential fear of aggression from conspecifics.

\section{Study limitations}

Our study was limited by the inclusion of a single unhabituated group (Congo). Clearly, multiple groups of this category would be needed to verify the effect of habituation across wild monkeys. Moreover, the fact that the Lemon Tree group showed as equally low habituation index as the Kubu group despite the fact that monkeys in Lemon Tree have been regularly exposed to researchers for 3 years more than Kubu raises the question of to what extent within group dynamics potentially influence the monkey's response to novelty. Kubu is a small group with a large proportion of juveniles and in many species, vervet monkeys included, juveniles seem to be more explorative than adults (Fairbanks and McGuire 1993; Bergman and Kitchen 2009; Thornton and Samson 2012; Debeffe et al. 2013). Considering within group dynamics, it will also help to evaluate what effects life-history and sociality have on curiosity. Thus, in the future, we intend to investigate these data at the individual level to clarify how potential within group variation may also contribute to the observed pattern between groups.

\section{Conclusion}

One way to detect curiosity in animals is to introduce something novel into their familiar environment and measure their motivation to overcome potential neophobia and explore it. In doing so, we found evidence that curiosity in vervet monkeys is expressed through a combination of reduced neophobia (willingness to approach into close proximity) together with a variety of explorative behaviours like smelling, touching, and tasting something previously unknown (Table 2). Our findings, that captive and wild-habituated vervet monkeys responded more positively towards unfamiliar items than unhabituated conspecifics, despite the fact that all wild monkeys are exposed to similar risks in their natural habitat, support our conclusion that the main driver of curiosity in our sample was habituation level to humans and human-made artefacts, rather than risk constraints or time constraints of life in the wild. Consequently, our findings highlight the importance to account for the captivity effect and habituation levels when conducting cognitive research across settings.

Supplementary Information The online version contains supplementary material available at https://doi.org/10.1007/s10071-021-01589-y. 
Acknowledgements We are extremely thankful to the research manager Michael Henshall at the IVP and all the volunteers that contributed and assisted our data collection. We are grateful to the van der Walt's family for permission to conduct the study in their reserve. We also dedicate a special thanks to Sandi Cronk at W. A. T. C. H. vervet rehabilitation centre, for her hospitality and collaboration during our stay at the sanctuary. Finally, we thank the Wenner-Gren Foundation, USA and the Waldemar von Frenckell Foundation, Fin to SF and the Swiss National Science Foundation (PP00P3_170624) to EvdW for their financial support for this study. We also would like to thank our reviewers and editor for their feedback that helped improve the manuscript.

Author contributions SF: conceptualization of the study, acquired funding, designing experiments, collected the data, and main writer of the manuscript. AM-R: statistical analyses, text editing, and manuscript writing. PD: assistance by data collection and text editing. TM: assistance by data collection. EvdW: supervisor, provided resources and funding for the study to take place at the IVP, and manuscript editing.

Funding Open access funding provided by Swiss Federal Institute of Technology Zurich. SF: the Wenner-Gren Foundation, USA and the Waldemar von Frenckell Foundation, Finland. EvdW: the Swiss National Science Foundation (PP00P3_170624), Switzerland.

Data availability All data for these analyses can be found in the Open Science Framework with the link: https://osf.io/2cahn/?view_only= e1d66702bc544363b5ced2ae51d97af5.

Code availability The code employed in these analyses can be found in the Open Science Framework with the link: https://osf.io/2cahn/?view_ only=e1d66702bc544363b5ced2ae51d97af5.

\section{Declarations}

Conflict of interest The authors declare no conflict of interests.

Ethical approval We declare that all experiments performed for this study were conducted on sole observational basis. This research adhered to the "Guidelines for the use of animals in research" of Association for Study of Animal Behaviour and was approved by the relevant local authority, Ezemvelo KZN Wildlife, South Africa.

Consent to participate Not applicable.

Consent for publication Not applicable.

Open Access This article is licensed under a Creative Commons Attribution 4.0 International License, which permits use, sharing, adaptation, distribution and reproduction in any medium or format, as long as you give appropriate credit to the original author(s) and the source, provide a link to the Creative Commons licence, and indicate if changes were made. The images or other third party material in this article are included in the article's Creative Commons licence, unless indicated otherwise in a credit line to the material. If material is not included in the article's Creative Commons licence and your intended use is not permitted by statutory regulation or exceeds the permitted use, you will need to obtain permission directly from the copyright holder. To view a copy of this licence, visit http://creativecommons.org/licenses/by/4.0/.

\section{References}

Amici F, Caicoya AL, Majolo B, Widdig A (2020) Innovation in wild Barbary macaques (Macaca sylvanus). Sci Rep 10(1):1-2. https:// doi.org/10.1038/s41598-020-61558-2

Baayen RH, Davidson DJ, Bates DM (2008) Mixed-effects modeling with crossed random effects for subjects and items. J Mem Lang 59(4):390-412. https://doi.org/10.1016/j.jml.2007.12.005

Barnett SA (1958) Experiments on 'neophobia' in wild and laboratory rats. Br J Psychol 49(3):195-201. https://doi.org/10.1111/j.20448295.1958.tb00657.x

Barrett LP, Stanton LA, Benson-Amram S (2019) The cognition of 'nuisance' species. Anim Behav 147:167-177. https://doi.org/10. 1016/j.anbehav.2018.05.005

Bates D, Maechler M, Bolker B, Walker S (2014) lme4: linear mixedeffects models using Eigen and S4. R Packag Version 1:1-7

Benson-Amram S, Holekamp KE (2012) Innovative problem solving by wild spotted hyenas. Proc R Soc B Biol Sci 279(1744):40874095. https://doi.org/10.1098/rspb.2012.1450

Benson-Amram S, Weldele ML, Holekamp KE (2013) A comparison of innovative problem-solving abilities between wild and captive spotted hyaenas, Crocuta Crocuta. Anim Behav 85(2):349-356. https://doi.org/10.1016/j.anbehav.2012.11.003

Bergman TJ, Kitchen DM (2009) Comparing responses to novel objects in wild baboons (Papio ursinus) and geladas (Theropithecus gelada). Anim Cogn 12(1):63. https://doi.org/10.1007/ s10071-008-0171-2

Berlyne DE (1950) Novelty and curiosity as determinants of exploratory behaviour. Br J Psychol 41(1):68

Biondi LM, Bó MS, Vassallo AI (2010) Inter-individual and age differences in exploration, neophobia and problem-solving ability in a Neotropical raptor (Milvago chimango). Anim Cogn 13(5):701710. https://doi.org/10.1007/s10071-010-0319-8

Brown GE, Ferrari MC, Elvidge CK, Ramnarine I, Chivers DP (2013) Phenotypically plastic neophobia: a response to variable predation risk. Proc R Soc B Biol Sci 280(1756):20122712. https://doi.org/ 10.1098/rspb.2012.2712

Byrne RW (2013) Animal curiosity. Curr Biol 23(11):R469-R470

Canteloup C, Hoppitt W, van de Waal E (2020) Wild primates copy higher-ranked individuals in a social transmission experiment. Nat Commun 11(1):1. https://doi.org/10.1038/s41467-019-1420

Canteloup C, Cera MB, Barrett BJ, van de Waal E (2021) Processing of novel food reveal payoff and rank-biased social learning in a wild primate. Sci Rep 11:1-13. https://doi.org/10.1038/ s41598-021-88857-6

Carter AJ, Marshall HH, Heinsohn R, Cowlishaw G (2012) How not to measure boldness: novel object and antipredator responses are not the same in wild baboons. Anim Behav 84(3):603-609. https:// doi.org/10.1016/j.anbehav.2012.06.015

Cauchard L, Boogert NJ, Lefebvre L, Dubois F, Doligez B (2013) Problem-solving performance is correlated with reproductive success in a wild bird population. Anim Behav 85(1):19-26. https:// doi.org/10.1016/j.anbehav.2012.10.005

Damerius LA, Graber SM, Willems EP, van Schaik CP (2017a) Curiosity boosts orang-utan problem-solving ability. Anim Behav 134:57-70. https://doi.org/10.1016/j.anbehav.2017.10.005

Damerius LA, Forss SI, Kosonen ZK, Willems EP, Burkart JM, Call J, Galdikas BM, Liebal K, Haun DB, Van Schaik CP (2017b) Orientation toward humans predicts cognitive performance in orang-utans. Sci Rep 7(1):1-2. https://doi.org/10.1038/srep40052

Day RL, Coe RL, Kendal JR, Laland KN (2003) Neophilia, innovation and social learning: a study of intergeneric differences in callitrichid monkeys. Anim Behav 65(3):559-571. https://doi.org/ 10.1006/anbe.2003.2074 
Debeffe L, Morellet N, Cargnelutti B, Lourtet B, Coulon A, Gaillard JM, Bon R, Hewison AJ (2013) Exploration as a key component of natal dispersal: dispersers explore more than philopatric individuals in roe deer. Anim Behav 86(1):143-151. https://doi.org/ 10.1016/j.anbehav.2013.05.005

Dobson AJ (2002) An introduction to generalized linear models. Chapman Hall/CRC, Boca Raton

Fairbanks LA, McGuire MT (1993) Maternal protectiveness and response to the unfamiliar in vervet monkeys. Am J Primatol 30(2):119-129. https://doi.org/10.1002/ajp.1350300204

Forss SI, Schuppli C, Haiden D, Zweifel N, van Schaik CP (2015) Contrasting responses to novelty by wild and captive orangutans. Am J Primatol 77(10):1109-1121. https://doi.org/10.1002/ajp.22445

Forss SI, Koski SE, van Schaik CP (2017) Explaining the paradox of neophobic explorers: the social information hypothesis. Int J Primatol 38(5):799-822. https://doi.org/10.1007/s10764-017-9984-7

Forstmeier W, Schielzeth H (2011) Cryptic multiple hypotheses testing in linear models: overestimated effect sizes and the winner's curse. Behav Ecol Sociobiol 65(1):47-55. https://doi.org/10.1007/ s00265-010-1038-5

Fox RA, Millam JR (2007) Novelty and individual differences influence neophobia in orange-winged Amazon parrots (Amazona amazonica). Appl Anim Behav Sci 104(1-2):107-115. https:// doi.org/10.1016/j.applanim.2006.04.033

Gajdon GK, Fijn N, Huber L (2004) Testing social learning in a wild mountain parrot, the kea (Nestor notabilis). Anim Learn Behav 32(1):62-71

Greenberg RS (1990a) Feeding neophobia and ecological plasticity: a test of the hypothesis with captive sparrows. Anim Behav 39(2):375-379. https://doi.org/10.1016/S0003-3472(05)80884-X

Greenberg RS (1990b) Ecological plasticity, neophobia, and resource use in birds. Studies in Avian Biology

Greenberg RS (2003) The role of neophobia and neophilia in the development of innovative behaviour of birds. In: Reader SM, Laland KN (eds) Animal innovation. Oxford University Press, pp 175-196

Greenberg R, Mettke-Hofmann C (2001) Ecological aspects of neophobia and neophilia in birds. Current ornithology. Springer, Boston, pp 119-178

Greggor AL, Thornton A, Clayton NS (2015) Neophobia is not only avoidance: improving neophobia tests by combining cognition and ecology. Curr Opin Behav Sci 6:82-89. https://doi.org/10.1016/j. cobeha.2015.10.007

Greggor AL, Jolles JW, Thornton A, Clayton NS (2016a) Seasonal changes in neophobia and its consistency in rooks: the effect of novelty type and dominance position. Anim Behav 121:11-20. https://doi.org/10.1016/j.anbehav.2016.08.010

Greggor AL, Clayton NS, Fulford AJ, Thornton A (2016b) Street smart: faster approach towards litter in urban areas by highly neophobic corvids and less fearful birds. Anim Behav 117:123-133. https://doi.org/10.1016/j.anbehav.2016.03.029

Griffin AS, Tebbich S, Bugnyar T (2017) Animal cognition in a humandominated world. Anim Cogn 20:1-6. https://doi.org/10.1007/ s10071-016-1051-9

Gross ME, Zedelius CM, Schooler JW (2020) Cultivating an understanding of curiosity as a seed for creativity. Curr Opin Behav Sci 35:77-82. https://doi.org/10.1016/j.cobeha.2020.07.015

Gruber T, Clay Z, Zuberbühler K (2010) A comparison of bonobo and chimpanzee tool use: evidence for a female bias in the Pan lineage. Anim Behav 80(6):1023-1033. https://doi.org/10.1016/j. anbehav.2010.09.005

Hall BA, Melfi V, Burns A, McGill DM, Doyle RE (2018) Curious creatures: a multi-taxa investigation of responses to novelty in a zoo environment. PeerJ 6:e4454. https://doi.org/10.7717/peerj. 4454
Haslam M (2013) 'Captivity bias' in animal tool use and its implications for the evolution of hominin technology. Philos Trans R Soc B Biol Sci 368(1630):20120421. https://doi.org/10.1098/rstb. 2012.0421

Jarjour C, Evans JC, Routh M, Morand-Ferron J (2020) Does city life reduce neophobia? A study on wild black-capped chickadees. Behav Ecol 31(1):123-131. https://doi.org/10.1093/beheco/arz167

Kalan AK, Hohmann G, Arandjelovic M, Boesch C, McCarthy MS, Agbor A, Angedakin S, Bailey E, Balongelwa CW, Bessone M, Bocksberger G (2019) Novelty response of wild African apes to camera traps. Curr Biol 29(7):1211-1217. https://doi.org/10. 1016/j.cub.2019.02.024

Kaulfuß P, Mills DS (2008) Neophilia in domestic dogs (Canis familiaris) and its implication for studies of dog cognition. Anim Cogn 11(3):553-556. https://doi.org/10.1007/s10071-007-0128-x

Kidd C, Hayden BY (2015) The psychology and neuroscience of curiosity. Neuron 88(3):449-460. https://doi.org/10.1016/j.neuron. 2015.09.010

Kummer H, Goodall J (1985) Conditions of innovative behaviour in primates. Philos Trans R Soc Lond B Biol Sci 308(1135):203214. https://doi.org/10.1098/rstb.1985.0020

Laidre ME (2008a) Do captive mandrills invent new gestures? Anim Cogn 11(2):179-187. https://doi.org/10.1007/s10071-007-0121-4

Laidre ME (2008b) Spontaneous performance of wild baboons on three novel food-access puzzles. Anim Cogn 11(2):223-230. https://doi. org/10.1007/s10071-007-0104-5

Laland KN, Reader SM (1999) Foraging innovation in the guppy. Anim Behav 57(2):331-340. https://doi.org/10.1006/anbe.1998.0967

Loewenstein G (1994) The psychology of curiosity: a review and reinterpretation. Psychol Bull 116(1):75. https://psycnet.apa.org/. Doi: https://doi.org/10.1037/0033-2909.116.1.75

Martina C, Cowlishaw G, Carter AJ (2021) Individual differences in task participation in wild chacma baboons. Anim Behav 172:7391. https://doi.org/10.1016/j.anbehav.2020.11.020

McCune KB, Jablonski P, Lee SI, Ha RR (2019) Captive jays exhibit reduced problem-solving performance compared to wild conspecifics. R Soc Open Sci 6(1):181311. https://doi.org/10.1098/rsos. 181311

Mercier S, Neumann C, van de Waal E, Chollet E, de Bellefon JM, Zuberbühler K (2017) Vervet monkeys greet adult males during high-risk situations. Anim Behav 132:229-245. https://doi.org/ 10.1016/j.anbehav.2017.07.021

Mettke-Hofmann C (2014) Cognitive ecology: ecological factors, lifestyles, and cognition. Wiley Interdiscip Rev Cogn Sci 5(3):345360. https://doi.org/10.1002/wcs. 1289

Mettke-Hofmann C, Winkler H, Leisler B (2002) The significance of ecological factors for exploration andneophobia in parrots. Ethology $108(3): 249-272$

Misslin R, Cigrang M (1986) Does neophobia necessarily imply fear or anxiety? Behav Proc 12(1):45-50. https://doi.org/10.1016/03766357(86)90069-0

Morand-Ferron J, Cole EF, Rawles JE, Quinn JL (2011) Who are the innovators? A field experiment with 2 passerine species. Behav Ecol 22(6):1241-1248. https://doi.org/10.1093/beheco/arr120

Moretti L, Hentrup M, Kotrschal K, Range F (2015) The influence of relationships on neophobia and exploration in wolves and dogs. Anim Behav 107:159-173. https://doi.org/10.1016/j.anbehav. 2015.06.008

Overington SE, Cauchard L, Côté KA, Lefebvre L (2011) Innovative foraging behaviour in birds: what characterizes an innovator? Behav Proc 87(3):274-285. https://doi.org/10.1016/j.beproc. 2011.06.002

Rasolofoniaina BN, Kappeler PM, Fichtel C (2021) Neophobia and social facilitation in narrow-striped mongooses. Anim Cogn 24(1):165-175. https://doi.org/10.1007/s10071-020-01429-5 
Reader SM, Laland KN (2001) Primate innovation: sex, age and social rank differences. Int J Primatol 22(5):787-805

Rössler T, Mioduszewska B, O'Hara M, Huber L, Prawiradilaga DM, Auersperg AM (2020) Using an innovation arena to compare wild-caught and laboratory Goffin's cockatoos. Sci Rep 10(1):1-2. https://doi.org/10.1038/s41598-020-65223-6

Schielzeth H (2010) Simple means to improve the interpretability of regression coefficients. Methods Ecol Evol 1(2):103-113. https:// doi.org/10.1111/j.2041-210X.2010.00012.x

Seyfarth RM, Cheney DL, Marler P (1980) Monkey responses to three different alarm calls: evidence of predator classification and semantic communication. Science 210(4471):801-803. https:// doi.org/10.1126/science.7433999

Shaw RC, Boogert NJ, Clayton NS, Burns KC (2015) Wild psychometrics: evidence for 'general' cognitive performance in wild New Zealand robins, Petroica longipes. Anim Behav 109:101-111. https://doi.org/10.1016/j.anbehav.2015.08.001

Shumaker RW, Walkup KR, Beck BB (2011) Animal tool behavior: the use and manufacture of tools by animals. JHU Press, Baltimore

Sol D, Griffin AS, Bartomeus I, Boyce H (2011) Exploring or avoiding novel food resources? The novelty conflict in an invasive bird. PLoS ONE 6(5):e19535. https://doi.org/10.1371/journal.pone. 0019535

Stöwe M, Bugnyar T, Loretto MC, Schloegl C, Range F, Kotrschal K (2006) Novel object exploration in ravens (Corvus corax): effects of social relationships. Behav Proc 73(1):68-75. https://doi.org/ 10.1016/j.beproc.2006.03.015

R Core Team (2020) "R: 2019.” A language and environment for statistical computing version 3.1

Thatcher HR, Downs CT, Koyama NF (2019) Anthropogenic influences on the time budgets of urban vervet monkeys. Landsc Urban Plan 181:38-44. https://doi.org/10.1016/j.landurbplan.2018.09. 014

Thornton A, Samson J (2012) Innovative problem solving in wild meerkats. Anim Behav 83(6):1459-1468. https://doi.org/10.1016/j. anbehav.2012.03.018

Tryjanowski P, Møller AP, Morelli F, Biaduń W, Brauze T, Ciach M, Czechowski P, Czyż S, Dulisz B, Goławski A, Hetmański
$\mathrm{T}$ (2016) Urbanization affects neophilia and risk-taking at birdfeeders. Sci Rep 6(1):1-7. https://doi.org/10.1038/srep28575

van de Waal E, Bshary R (2011) Social-learning abilities of wild vervet monkeys in a two-step task artificial fruit experiment. Anim Behav 81(2):433-438. https://doi.org/10.1016/j.anbehav.2010.11.013

van de Waal E, Borgeaud C, Whiten A (2013) Potent social learning and conformity shape a wild primate's foraging decisions. Science 340(6131):483-485

van de Waal E, van Schaik CP, Whiten A (2017) Resilience of experimentally seeded dietary traditions in wild vervets: evidence from group fissions. Am J Primatol 79(10):e22687

van Horik JO, Langley EJ, Whiteside MA, Madden JR (2017) Differential participation in cognitive tests is driven by personality, sex, body condition and experience. Behav Proc 134:22-30. https:// doi.org/10.1016/j.beproc.2016.07.001

van Schaik CP, Burkart J, Damerius L, Forss SI, Koops K, Van Noordwijk MA, Schuppli C (2016) The reluctant innovator: orangutans and the phylogeny of creativity. Philos Trans R Soc B Biol Sci 371(1690):20150183. https://doi.org/10.1098/rstb.2015.0183

Veasey JS, Waran NK, Young RJ (1996) On comparing the behaviour of zoo housed animals with wild conspecifics as a welfare indicator. Anim Welf Potters BAR 5:13-24

Wang MZ, Hayden BY (2019) Monkeys are curious about counterfactual outcomes. Cognition 189:1-10

Wimberger K, Downs CT (2010) Annual intake trends of a large urban animal rehabilitation centre in South Africa: a case study. Anim Welf 19(4):501

Yamanashi Y, Hayashi M (2011) Assessing the effects of cognitive experiments on the welfare of captive chimpanzees (Pan troglodytes) by direct comparison of activity budget between wild and captive chimpanzees. Am J Primatol 73(12):1231-1238. https:// doi.org/10.1002/ajp.20995

Publisher's Note Springer Nature remains neutral with regard to jurisdictional claims in published maps and institutional affiliations. 